\title{
Taxonomies Support Preschoolers' Knowledge Acquisition from Storybooks
}

\author{
Ashley M. Pinkham, ${ }^{1}$ Tanya Kaefer, ${ }^{2}$ and Susan B. Neuman ${ }^{3}$ \\ ${ }^{1}$ School of Education, University of Michigan, 610 E. University Avenue No. 3113, Ann Arbor, MI 48109, USA \\ ${ }^{2}$ Faculty of Education, Lakehead University, 955 Oliver Road, Thunder Bay, ON, Canada P7B 5E1 \\ ${ }^{3}$ Department of Teaching and Learning, New York University, 239 Green Street, 2nd Floor, New York City, NY 10003, USA
}

Correspondence should be addressed to Ashley M. Pinkham; pinkhama@umich.edu

Received 28 August 2013; Revised 3 December 2013; Accepted 21 January 2014; Published 25 March 2014

Academic Editor: Dorit Ravid

Copyright (C) 2014 Ashley M. Pinkham et al. This is an open access article distributed under the Creative Commons Attribution License, which permits unrestricted use, distribution, and reproduction in any medium, provided the original work is properly cited.

\begin{abstract}
For young children, storybooks may serve as especially valuable sources of new knowledge. While most research focuses on how extratextual comments influence knowledge acquisition, we propose that children's learning may also be supported by the specific features of storybooks. More specifically, we propose that texts that invoke children's knowledge of familiar taxonomic categories may support learning by providing a conceptual framework through which prior knowledge and new knowledge can be readily integrated. In this study, 605 -year olds were read a storybook that either invoked their knowledge of a familiar taxonomic category (taxonomic storybook) or focused on a common thematic grouping (traditional storybook). Following the book-reading, children's vocabulary acquisition, literal comprehension, and inferential comprehension were assessed. Children who were read the taxonomic storybook demonstrated greater acquisition of target vocabulary and comprehension of factual content than children who were read the traditional storybook. Inferential comprehension, however, did not differ across the two conditions. We argue for the importance of careful consideration of book features and storybook selection in order to provide children with every opportunity to gain the knowledge foundational for successful literacy development.
\end{abstract}

\section{Introduction}

One of the most important predictors of young children's literacy development and lifelong academic achievement is their knowledge base $[1,2]$. For example, the depth and breadth of children's background knowledge is positively related to both their vocabulary knowledge and oral language comprehension, and these relationships appear to be mutually reinforcing $[3,4]$. Children's prior knowledge may support their learning in a number of ways. First, prior knowledge may help create expectations, thereby directing children's attention toward information that is especially relevant or important. Knowledge may also facilitate their comprehension by providing a stable framework for memory encoding and retrieval. Finally, prior knowledge may also help children fill in informational gaps, allowing them to maintain coherence and enhance their representations of new information. When children possess accurate background knowledge about a topic, they may demonstrate superior inference-making and learning relative to instances in which their knowledge is incorrect, inaccessible, or lacking (see [5] for review).

For preschoolers, books may be a valuable resource for gaining knowledge about the world. Books can extend human memory, allowing children to learn about things they may have never seen, places they may have never visited, and events that may have happened hundreds of years ago. As a result, children who read more are often assumed to have greater opportunities to develop the breadth and depth of their knowledge base [6] and acquire information capital [7]. Given that books can provide children with important learning opportunities, a crucial question is, how to best facilitate their acquisition of new knowledge from book-reading experiences. One possibility is to focus on improving the quality of extratextual interactions. In fact, the vast majority of researches on young children's experiences with books 
have focused on the nature of the adult-child interaction. This is consistent with the perspective that learning is a socially mediated process [8], and that one of the primary functions of shared book-reading is the coconstruction of meaning through extratextual adult-child conversations [9]. Yet despite the research emphasis on shared-reading, recent meta-analyses have reported that the overall educational benefits of such experiences may be limited, particularly for children younger than 6 years of age $[10,11]$. This may be related to the fact that adults often do not focus on scaffolding children's knowledge acquisition during these interactions. Newman [12], for example, proposed that the primary role of shared-reading, especially in home contexts, may not be the acquisition of factual information or building literacy skills, but rather the transmission of cultural values. As a result, such shared-reading interactions may be more relevant to children's sociocultural development than their knowledge development.

An alternative (although not mutually exclusive) strategy for facilitating children's knowledge acquisition may be to focus on the features of the books themselves. A book's text can be a valuable educational tool if, for example, it provides readers with language and information that may not otherwise be available to them or shared with children. Furthermore, because adult readers possess varying skills and knowledge, the scaffolding they do provide for children during shared-reading may not be of uniformly high quality. The specific features of a book may thus be particularly important when extratextual supports are insufficient or nonexistent, such as during lower-quality shared-reading or independent reading experiences $[5,13,14]$.

Taxonomic categorization is one potentially powerful feature that may be readily integrated into storybook texts. Broadly speaking, taxonomies are hierarchical structures based on shared superordinate categories or functions [15]. For example, birds, dogs, and whales are taxonomically related because they belong to the same superordinate category (i.e., animals); pigeons, penguins, and flamingos are taxonomically related because they belong to the same basic level (i.e., birds) and, by extension, superordinate (i.e., animals) categories. These categories are typically universal (e.g., birds are animals in North America as well as Europe), conventional (e.g., most people agree that birds are animals), and constant (e.g., birds remain animals even if their feathers are plucked) $[16,17]$. Taxonomic categorization may support learning by providing a conceptual framework through which knowledge is encoded, organized, and remembered. In this way, taxonomies may help connections be made between prior knowledge and new information, as well as support fluent access to information related to those categories [1820]. This, in turn, may facilitate the successful construction of meaning, a crucial step for word learning, and oral language comprehension $[21,22]$. Young children may especially benefit when information is organized into such meaningful networks. Recent research suggests that there may be a strong reciprocal relationship between children's language development and their hierarchical conceptualization [23]. In our work, for example, we have found that invoking category membership during the learning process appears to provide preschoolers with a rich conceptual and semantic background that mutually benefited their acquisition of vocabulary and category-related content [24-26].

In addition to providing a meaningful conceptual framework, taxonomies may also support children's learning by scaffolding their ability to draw inferences about texts. Such inference-making is a especially critical skill for comprehension. During book-reading, for example, children must be able to go beyond the information directly provided in the text in order to fill in information necessary for comprehending the narrative or elaborating on given information [27]. Because they are hierarchically nested, invoking taxonomic category membership may help scaffold children's ability to make inferences about content that has only been provided implicitly by the text. This powerful ability to facilitate children's inference-making is referred to as the "inductive potential" of taxonomic categories $[28,29]$. If children know that animals need food to survive, for example, they may be able to make inferences about category members at increasingly specific levels: birds are animals; therefore birds need food to survive; penguins are birds, birds are animals, therefore penguins need food to survive, and so forth. When reading the statement "the penguin caught a fish to give to its chick," children may thus be able to use their taxonomic knowledge in order to draw the correct inference (i.e., the chick will consume the fish as food) and comprehend the text.

In this study, we examined the unique potential of taxonomic categories to bootstrap children's knowledge development during book-reading experiences. More specifically, we investigated the extent to which storybooks that invoke prior knowledge of taxonomic categories served to support preschoolers' vocabulary acquisition and comprehension in the absence of extratextual scaffolding. This was addressed through a series of three research questions.

(1) What is the effect of book-reading on children's vocabulary acquisition and comprehension in the absence of extratextual scaffolding?

(2) To what extent does invoking children's preexisting knowledge of a taxonomic category help bootstrap their subsequent knowledge acquisition from storybooks?

(3) Does invoking children's taxonomic category knowledge scaffold their ability to draw inferences about the implicit content of storybooks?

\section{Method}

2.1. Participants. Participants were 605 -year-old children (M $=62.63$ months, $\mathrm{SD}=2.07 ; 33$ boys and 27 girls) assessed during the summer prior to kindergarten entry. Children were Caucasian (68\%), African American (25\%), Asian (3\%), and bi/multiracial (4\%); all were native English speakers. Children were recruited as part of a larger study aimed at improving children's vocabulary and conceptual study. The study was conducted in 20 preschool classrooms at eight sites [3]. A subset of children were randomly selected from the larger sample and represented a range of socioeconomic 


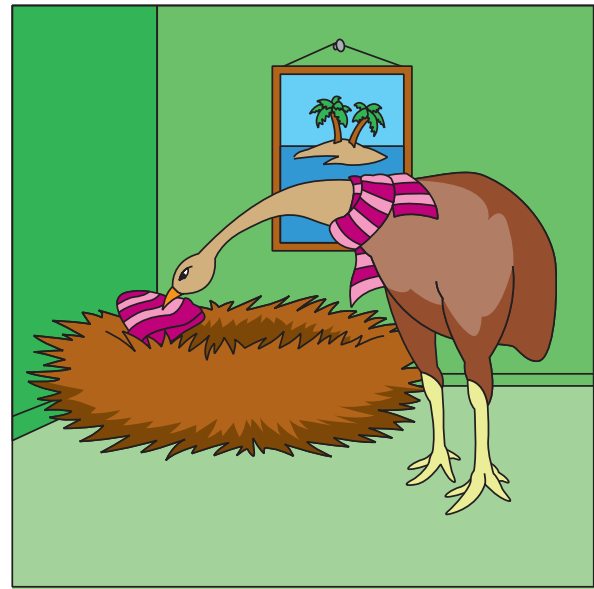

A moa builds a nest because it is a bird. The moa looked in its nest and found its hat.

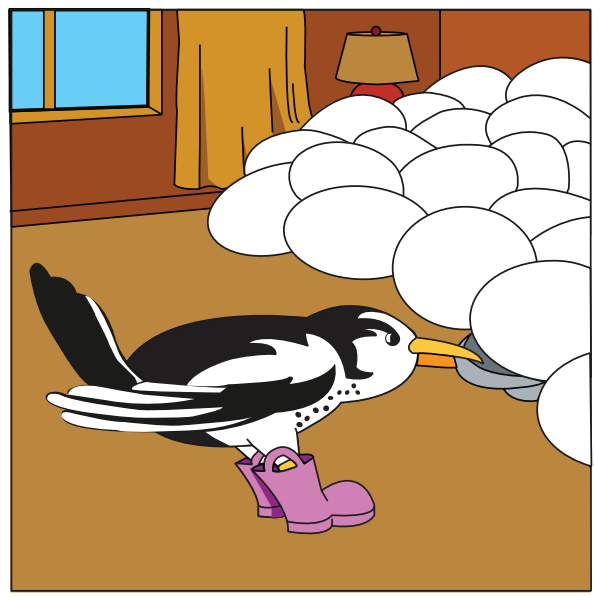

A faroe lays eggs because it is a bird. The faroe looked under its eggs and found its hat.

(a)

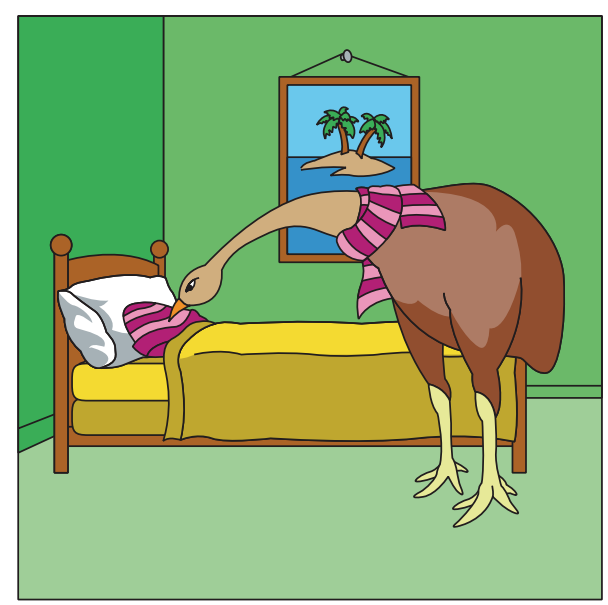

A moa has a bed and lives in a house. The moa looked in its bed and found its hat.

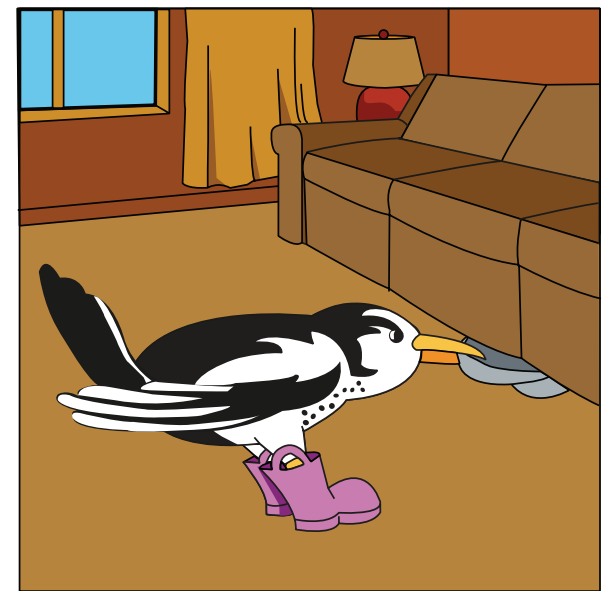

A faroe has a sofa and lives in a house.

The faroe looked under its sofa and found its hat.

(b)

FIGURE 1: Sample pages from the (a) taxonomic storybook and (b) traditional storybook.

backgrounds: $38 \%$ were enrolled in Head Start centers for children from high-risk backgrounds; $47 \%$ attended statesponsored prekindergarten, and 15\% attended tuition-based preschools.

\subsection{Design and Materials}

2.2.1. Target Vocabulary. Four species of extinct bird served as unfamiliar target vocabulary words: cupido, faroe, kona, and moa. These words were selected because "bird" is a familiar taxonomic category for most preschoolers [30, 31], yet the extinction status of these species helps ensure their unfamiliarity (see also [3]).

2.2.2. Storybooks. We created two 18-page illustrated books appropriate for young children. The books shared a common plot and story grammar, including the setting (i.e., house), problem (i.e., needing to wear hats to go outside in the snow), response (i.e., searching for hats), and outcomes (i.e., finding hats and happily playing outside) $[32,33]$.

Children were randomly assigned to one of two betweenparticipants conditions. In the taxonomic storybook condition, children's prior knowledge of a familiar taxonomic category (i.e., birds) was invoked through basic-level generic noun phrases [34] and references to causal properties [35]. Characteristic properties of the taxonomic category (e.g., lays eggs, builds nests) were included in critical story events throughout the text. In the traditional storybook condition, the book focused on a common thematic grouping based on a complementary external relation (i.e., things found in a house) [36]. Members of the thematic grouping (e.g., bed, sofa) were included in critical story events. Books in both conditions made three references to each of the four target words. In the taxonomic storybook, target words were explicitly linked to causal, essential properties of members of the taxonomic category (e.g., a faroe lays eggs because it is a bird). In the traditional storybook, target words were linked 


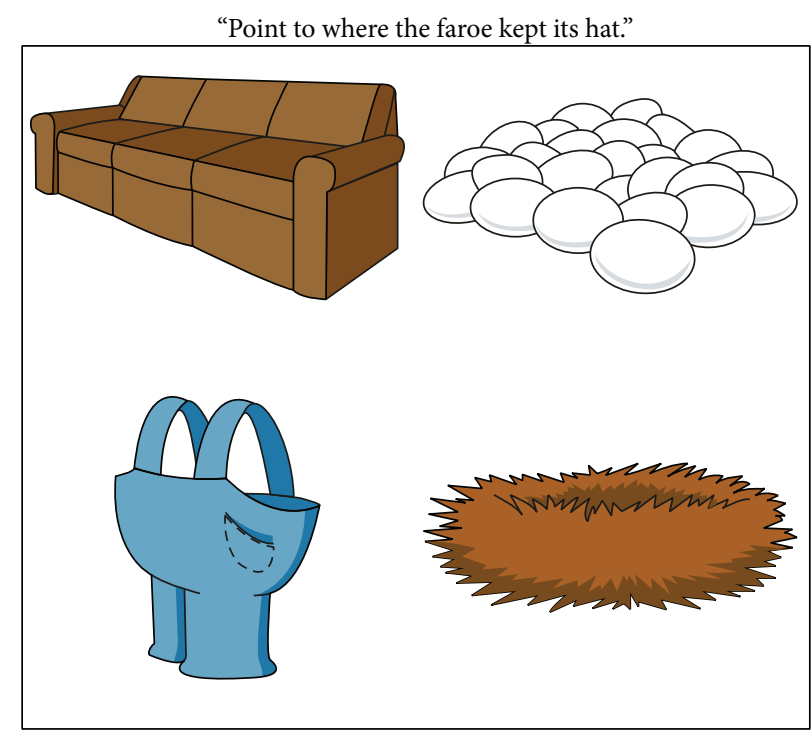

(a)

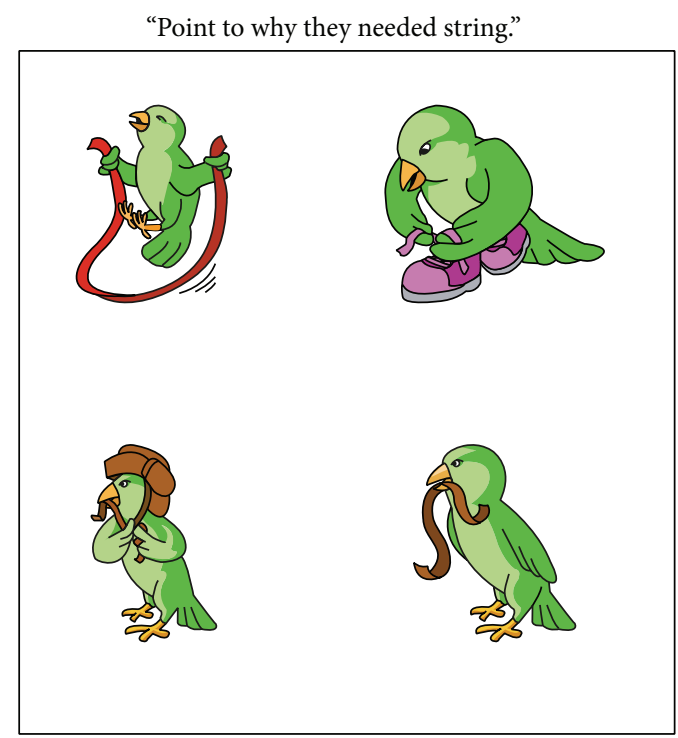

(b)

FIGURE 2: Sample test items from the (a) literal content and (b) inferential comprehension assessments.

to members of the thematic category (e.g., a faroe has a sofa and lives in a house). See Figure 1 for sample illustrations and text from each storybook.

\subsection{Child Assessments}

2.3.1. Target Vocabulary. To measure children's knowledge of the target vocabulary words, we modeled a 4 -item receptive vocabulary assessment after the Peabody Picture Vocabulary Test [37]. Children were presented with a directive (e.g., "Point to the faroe") and asked to select the referent from a grid of four professionally drawn color illustrations. To ensure that children learned the target vocabulary words rather than simply recalling category membership, the illustrations all belonged to the same basic level category: the correct referent (e.g., faroe), a familiar foil from the book (e.g., moa), and two unfamiliar foils (e.g., two novel bird species). Illustrations were depicted without contextual information against a white background. Assessment items were randomized and then administered in a set order across participants. Responses were scored dichotomously (i.e., correct or incorrect), summed to yield an overall score (ranging from 0 to 4), and converted into a proportion score. Internal consistency was Kuder-Richardson $\rho=0.44$, which is within the acceptable range for researcher-developed measures [38].

2.3.2. Literal Comprehension. To measure children's understanding of the factual content explicitly presented in the text, we created a 5-item literal comprehension assessment. Children were presented with a directive (e.g., "Point to where the faroe kept its hat") and asked to indicate their response from a grid of four professionally drawn color illustrations: the correct response, a familiar foil from the book, and two unfamiliar foils (see Figure 2). Assessment items were randomized and then administered in a set order across participants. Responses were scored dichotomously (i.e., correct or incorrect), summed to yield an overall score (ranging from 0 to 5), and converted into a proportion score. Internal consistency was Kuder-Richardson $\rho=0.46$ [38].

2.3.3. Inferential Comprehension. To assess children's ability to draw inferences about implicit content, we created a 5item inferential comprehension assessment. For example, the storybooks included the following text:

The birds [friends] did not want the squirrel to take their hats. They said, "If we tie our hats to our heads, he cannot steal them!" The birds [friends] went to look for string.

To fully comprehend this text, children must go beyond explicit content (i.e., the characters wanted to tie hats to their heads; they looked for string) to draw inferences about implicit content (i.e., the characters needed string to tie their hats to their heads).

Children were presented with a directive (e.g., "Point to why they needed string") and asked to select their response from a grid of four professionally drawn color illustrations: the correct response, a familiar foil from the book, and two unfamiliar foils (see Figure 2). Assessment items were randomized and then administered in a set order across participants. Responses were scored dichotomously (i.e., correct or incorrect), summed to yield an overall score (ranging from 0 to 5), and converted into a proportion score. Internal consistency was Kuder-Richardson $\rho=0.33$ [38].

2.3.4. General Vocabulary Knowledge. Children's general vocabulary knowledge was measured with the Peabody Picture Vocabulary Test-III (PPVT-III), a receptive vocabulary test yielding both raw scores and standard equivalent scores related to national norms [37]. The reported reliability for the 
TABLE 1: Descriptive statistics by condition $(N=60)$.

\begin{tabular}{|c|c|c|c|c|c|c|}
\hline & \multicolumn{3}{|c|}{ Taxonomic Storybook $(n=29)$} & \multicolumn{3}{|c|}{ Traditional Storybook $(n=31)$} \\
\hline & M & SD & Range & M & SD & Range \\
\hline Target vocabulary* & 0.33 & 0.24 & $0-0.75$ & 0.19 & 0.22 & $0-0.75$ \\
\hline Literal comprehension* & 0.63 & 0.25 & $0-1.00$ & 0.49 & 0.28 & $0-1.00$ \\
\hline $\begin{array}{l}\text { Inferential } \\
\text { comprehension }\end{array}$ & 0.42 & 0.22 & $0.20-0.80$ & 0.43 & 0.28 & $0-1.00$ \\
\hline PPVT-III & 95.00 & 14.14 & $67.00-128.00$ & 100.42 & 13.81 & $63.00-123.00$ \\
\hline
\end{tabular}

Note: ${ }^{*} P<0.05$; PPVT-III: Peabody Picture Vocabulary Test-III (L. Dunn and L. Dunn, 1998 [37]).

PPVT-III ranges from 0.91 to 0.94 . Standard scores were used in all analyses.

2.4. Procedure. Children were tested individually in a quiet space in their classroom. The experimenter was a trained research assistant blind to the study's hypotheses. They were seated adjacent to the experimenter, either at a childsized table or on the floor, while the experimenter read the book aloud. To create an explicit pedagogical context, the experimenter provided ostensive cues, such as pointing, exaggerated prosody, and joint attention [39]. However, the experimenter did not provide any extratextual comments throughout the book-reading; children heard only the book text.

Children were read the storybooks three times, resulting in a total of nine exposures to each of the four target vocabulary words. Repeated reading may provide children with additional opportunities to encode new information and notice deeper conceptual properties, thereby facilitating their ability to store and transfer knowledge [40-42]. Moreover, since children were more familiar with the general narrative plot during the second and third readings, they may have been able to allocate greater attention to learning the specific information conveyed in the text [43].

Immediately following the final reading of the book, children completed the target vocabulary, literal comprehension, inferential comprehension, and PPVT assessments. Assessments were administered in a set order across participants. The complete procedure lasted approximately 20 minutes.

\section{Results}

Descriptive statistics (means, standard deviations, and ranges) are presented in Table 1. Preliminary analyses revealed no significant effects or interactions involving gender or socioeconomic status (i.e., preschool type). These factors were therefore not considered in subsequent analyses.

3.1. What Is the Effect of Book-Reading on Children's Vocabulary Acquisition and Comprehension in the Absence of Extratextual Scaffolding? Our first research question addressed whether children were able to acquire new vocabulary and comprehend the factual content of storybooks in the absence of extratextual scaffolding by an adult reader. We first examined children's performance on the target vocabulary assessment. A one-sample $t$-test indicated that, overall, children did not learn a significantly greater proportion of target vocabulary words than that expected by chance (i.e., $0.25), t(59)=0.27, P=0.394$, one-tailed. This, however, appeared to vary across conditions. While children who were read the traditional storybook did not perform significantly different from chance $(t(30)=-1.42, P=0.083$, one-tailed), those who were read the taxonomic storybook did learn a significantly greater proportion of target vocabulary words than expected by chance $(t(28)=1.73, P=0.048$, onetailed). This suggests that children may have been able to acquire new vocabulary from the taxonomic storybook, but not the traditional storybook, without receiving extratextual scaffolding from an adult reader.

We next examined children's performance on the literal comprehension assessment. Overall, children demonstrated greater comprehension of factual content than expected by chance (i.e., 0.25$), t(59)=8.81, P<0.00025$, one-tailed. This pattern of results held for children in both the taxonomic storybook $(t(28)=8.25, P<0.00025$, one-tailed $)$ and traditional storybook conditions $(t(30)=4.83, P<0.00025$, one-tailed). These results suggest that children were able to comprehend the factual content of both storybooks in the absence of extratextual scaffolding.

3.2. To What Extent Does Invoking Children's Preexisting Knowledge of a Taxonomic Category Help Bootstrap Their Subsequent Knowledge Acquisition from Storybooks? We next investigated the extent to which invoking children's knowledge of a familiar taxonomic category may have facilitated their target vocabulary acquisition and literal comprehension. To do so, we conducted a series of one-way analyses of covariance (ANCOVA) with condition as a betweenparticipants independent factor. Because children's existing vocabulary knowledge is often related to their acquisition of new vocabulary and factual content $[5,44]$, general vocabulary knowledge (i.e., PPVT) was included as a covariate in each analysis.

First, we examined children's performance on the target vocabulary assessment. Our analysis revealed that PPVT was not a significant covariate $(F(1,57)=0.93, P=$ 0.339 ). As shown in Figure 3 , there was a significant main effect of condition on children's target vocabulary knowledge $(F(1,57)=5.70, P=0.020)$. The effect size was $\eta^{2}=0.09$, indicating a moderate effect [45]. This indicates that children who were read the taxonomic storybook learned a greater 


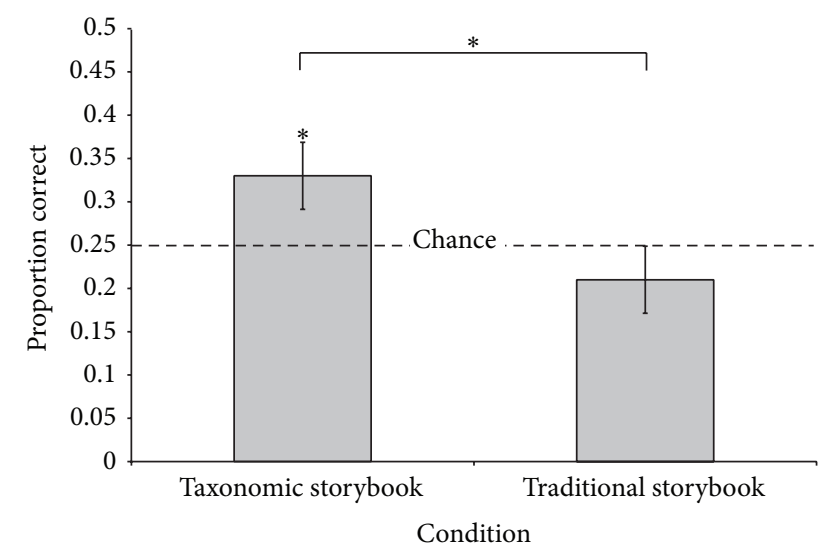

FIGURE 3: Children's performance on the target vocabulary assessment (by condition). Note. ${ }^{*} P<0.05$.

proportion of target vocabulary words than children who were read the traditional storybook.

We then examined children's performance on the literal comprehension assessment. Our analysis revealed PPVT as a significant covariate $(F(1,57)=10.32, P=0.002)$. As Figure 4 shows, there was also a significant main effect condition on children's performance on the literal comprehension assessment $(F(1,57)=8.11, P=0.006)$. The effect size was $\eta^{2}=0.13$, indicating a moderately large effect [45]. This indicates that children in the taxonomic storybook condition appeared to demonstrate greater comprehension of factual content than children in the traditional storybook condition. Taken together, these results suggest that children's ability to acquire vocabulary and content knowledge from storybooks may depend, in part, on how the book introduces new information.

\subsection{Does Invoking Children's Taxonomic Category Knowledge} Scaffold Their Ability to Draw Inferences about the Implicit Content of Storybooks? Our last research question examined whether inducing children's knowledge of a familiar taxonomic category scaffolded their ability to draw inferences about implicit content. To examine this, we conducted a oneway ANCOVA on the inferential comprehension assessment with condition as a between-participants independent factor. Because children's inference-making ability is often related to their vocabulary size [46], general vocabulary knowledge (PPVT) was included as a covariate; however, it was not significant $(F(1,57)=1.11, P=0.296)$. Our analysis did not reveal a significant main effect of condition on children's performance on the inferential comprehension assessment $\left(F(1,57)=0.02, P=0.899, \eta^{2}<0.01\right)$. This indicates that children who were read the taxonomic storybook did not demonstrate greater inferential comprehension than children who were read the traditional storybook. Both groups, however, performed significantly greater than expected by chance $(0.25)$ (taxonomic: $t(28)=4.25, P<0.00025$, onetailed; traditional: $t(30)=3.48, P<0.00025$, one-tailed). Collectively, these results suggest that children were able to successfully draw inferences about the implicit content of

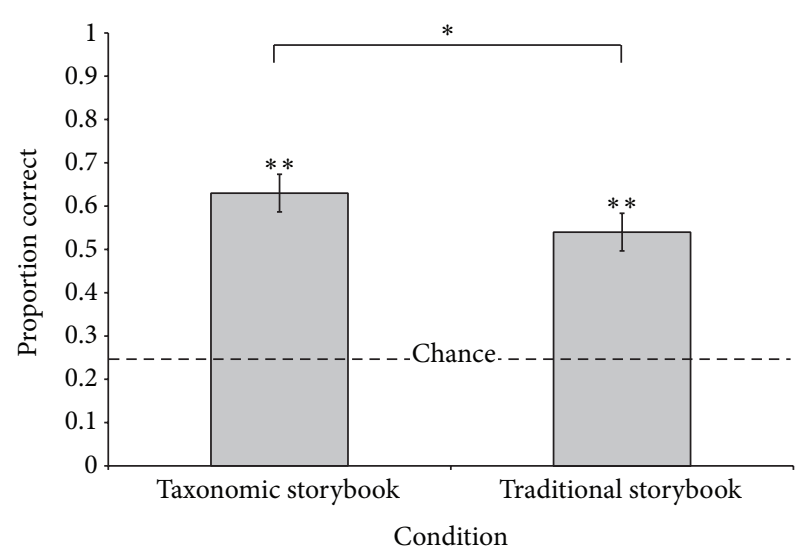

FIGURE 4: Children's performance on the literal comprehension assessment (by condition). Note. ${ }^{*} P<0.05 ;{ }^{* *} P<0.01$.

the book, and their inferential comprehension appeared to be independent of the support provided by invoking their taxonomic category knowledge.

\section{Discussion}

The depth and breadth of children's knowledge base provide a crucial foundation for successful literacy development and academic achievement $[1,2]$. For children, storybooks may be a especially valuable source of new knowledge [14]. Previous research has shown that preschoolers' knowledge acquisition may be scaffolded by shared-reading experiences, particularly when adult readers provide them with highquality extratextual comments $[47,48]$. The present study demonstrated that learning may also be positively affected by the features of the text. Specifically, we found that books that invoked taxonomic category membership appeared to facilitate the acquisition of new vocabulary and content knowledge. For young children, how books present new information may be as influential to their learning as how adults discuss that information with them.

We propose that books that invoke the reader's taxonomic category knowledge may serve as especially powerful knowledge-building supports for at least three reasons. First, taxonomic categories may provide children with a general conceptual framework through which new information can be readily encoded and remembered $[18,20]$. As a result, the taxonomic storybook may have helped children integrate their preexisting knowledge with newly acquired information-an essential step for word learning and oral language comprehension [21, 22]. Second, the inductive potential of taxonomic categories may have allowed children to make inferences that went beyond the information explicitly described in the storybook $[28,29]$. In this way, the taxonomic storybook may have supported children's comprehension by helping them fill in the information needed to understand and enhance their representation of the text. Third, in order to efficiently construct meaning and develop a coherent understanding of a text, children are unlikely to need to make connections between each piece of information 
presented in the book and all of their preexisting background knowledge. Instead, they may be able to utilize heuristics to help focus their efforts. For example, children may rely on pedagogical supports, such as illustrations [49] or materialsbased ostensive features [50,51], to help direct their attention to valuable educational content. When reading the taxonomic storybook, repeated references to the familiar taxonomic category may have similarly served as a salient pedagogical cue.

For taxonomic storybooks to serve as valuable knowledge-building supports, children must already possess sufficient knowledge about the target taxonomic category, as well as the nature of taxonomies more generally. In the current study, we specifically selected "birds" because most preschoolers are already familiar with the taxonomic category and can successfully draw inferences based on their category knowledge [30,31]. Nonetheless, children's knowledge of even a familiar category may vary widely across individuals, which may in turn affect their subsequent knowledge acquisition. Children's extant "bird" knowledge may have therefore influenced the extent to which the taxonomic storybook scaffolded their vocabulary acquisition and comprehension. Recent work in our lab, for example, has focused on explicating the relationship between children's preexisting knowledge and their word learning. In a series of recent experiments, for example, Kaefer et al. [3] assessed preschoolers' incidental word learning from illustrated storybooks. When the text was about a common taxonomic category, children who were more knowledgeable about the category demonstrated greater word learning and comprehension than their lessknowledgeable peers. However, when children's background knowledge was equated through the use of a novel category, the differences disappeared. This suggests that variability in children's preexisting knowledge may profoundly impact their subsequent learning and highlights the importance of helping young children construct a broad knowledge base in the early childhood years.

Although inducing knowledge of a familiar taxonomic category may have supported children's vocabulary acquisition and literal comprehension, reading the taxonomic storybook did not appear to substantially bootstrap their inferential comprehension. Previous research suggests that children may not easily acquire new information by inference, particularly when they are younger than 10 years of age [52]. It is therefore possible that the preschoolers in our study struggled to draw inferences about the implicit content of the book. Across both conditions, however, their performance was significantly above chance, suggesting that they were not simply guessing on assessment items. An alternative possibility is that the items on the inferential comprehension assessment may not have specifically required children to access their taxonomic category knowledge, thereby limiting the potential benefit of the experimental manipulation. Consider, for example, "the moa looked in his nest and found his hat." To comprehend this statement, children may have had to access their real-world knowledge to draw the correct inference-that is, that the moa stored his hat in his nest-without needing to access their taxonomic bird knowledge per se. Consistent with this interpretation, Pike et al. [53] recently demonstrated that pedagogical supports, such as storybook illustrations, may only facilitate children's inferential comprehension when they are directly related to the content necessary for making the correct inference. Additional research is thus needed to address the extent to which taxonomic storybooks may help support inferential comprehension when children are specifically required to access their knowledge of taxonomic categories.

Our results are particularly important given the lowintensity nature of the book-reading experience. Because we were specifically interested in the effect of specific features of the book on children's knowledge acquisition, experimenters simply read the storybooks aloud; indeed, they intentionally provided no extratextual comments at all. Nevertheless, children appeared to learn a greater proportion of target vocabulary and demonstrated greater comprehension of the book's content when the text invoked their preexisting taxonomic category knowledge. Intriguingly, these effects were stronger than those reported in many shared-reading interventions $[10,11]$. And unlike many shared-reading interventions that focus primarily on the quality of extratextual conversations, a taxonomic storybook may help scaffold children's conceptual organizational structure and knowledge acquisition even when the adult reader cannot or does not. Given that preschool and early elementary teachers typically devote less than 11 minutes per day to reading books aloud with their students [54], this limited time must be used efficiently to ensure that children have the greatest opportunity to gain knowledge. Storybooks capable of efficiently bootstrapping learning may thus be particularly valuable in early childhood education settings.

Nonetheless, it remains possible that taxonomic storybooks may serve as even more valuable educational tools when accompanied by high-quality extratextual scaffolding. During shared-reading, an adult's extratextual comments may serve to scaffold content, thereby facilitating children's comprehension, learning, and retention of both factual information and inferred information presented within the text $[9,27]$. Taxonomic storybooks may be especially effective when complemented by related extratextual comments, such as discussing the properties of taxonomic categories. In one recent intervention, for example, preschoolers especially benefited from shared book-reading experiences in which the teacher made explicit connections between new words and their related concepts $[55,56]$. Books that effectively promote such discussions between children and adults may be particularly valuable knowledge-building supports. Future research is needed, however, to fully address the potential additive effects of high-quality extratextual conversations and books structured to invoke children's taxonomic knowledge.

Although inducing children's taxonomic knowledge appeared to scaffold their learning from our specially designed storybooks, the present study only assessed children's knowledge immediately following the bookreading experience. For books to be a truly effective source of new knowledge, however, children must not only comprehend and recall the book's content; they must also be able to generalize and extend their knowledge between the book and the real world. In recent work, Ganea and 
colleagues [40] investigated the extent to which young children are able to extend the information that they learned from books to new exemplars. After being read an informational book about color camouflage in frogs, 4-year olds were able to use the information to explain a similar situation in a book about butterflies. Moreover, they were also able to extend their knowledge about color camouflage from book illustrations to live animals, such as lizards and crabs. These findings suggest that preschoolers are indeed capable of generalizing the information introduced in books to other contexts.

It should be noted that the children in [40] demonstrated knowledge transfer from an informational text illustrated with realistic photographs. Information books typically contain specific language and genre features, such as explicit labeling and summarizing of major ideas, which may encourage children's ability to use them as sources of new knowledge $[57,58]$. In the present study, however, we were specifically interested in narrative storybooks because they are the most common type of book selected by adults to read with young children [59]. Narrative or narrative-informational books may indeed be rich sources of language and new information for children. However, by using fantasy contexts or characters to teach information meant to be applied in the real world, such books may limit children's knowledge generalization and transfer due to a fundamental dissimilarity with the real world. In fact, preschoolers conceptualize fictional words (e.g., the world of SpongeBob or Batman) as distinct and separate from the real world [60] and are better able to transfer knowledge learned from stories about real people or entities than stories about fictional characters [61]. Given this, it is possible that our results may have, in fact, underestimated children's ability to gain knowledge from reading the storybooks. Furthermore, our previous work [25] suggests that reading narrative-informational books may help support children's subsequent use of information texts as knowledgebuilding supports. Nonetheless, future research is needed to more fully address the role of genre features on preschoolers' knowledge acquisition from books.

\section{Conclusions}

Given the ubiquity of book-reading experiences during early childhood, storybooks have the capability to help build children's knowledge base and, by extension, support their early literacy development. However, the majority of traditional shared-reading interventions appear to have limited effects on children's knowledge development $[9,10]$. We suggest that books that explicitly invoke taxonomic category membership have the unique potential to facilitate children's knowledge acquisition by providing a conceptual framework through which their prior knowledge can be organized and integrated with new information. Moreover, during sharedreading experiences, such books may help provide parents and teachers with the language and information that may not otherwise be available to them or shared with children. Although only a first step, this study clearly demonstrates the importance of focusing on book features during the careful selection of storybooks in order to provide children with every opportunity to gain the knowledge foundational for literacy development and academic achievement throughout the school years.

\section{Conflict of Interests}

The authors declare that there is no conflict of interests regarding the publication of this paper.

\section{Acknowledgments}

Portions of this work were presented at the semiannual meeting of the Society for Research on Educational Effectiveness, March, 2011, Washington, DC, and the biennial meeting of the Society for Research in Child Development, April 2011, Montreal, QC, Canada. The authors gratefully acknowledge funding from the Institute of Education Sciences (Grants R305A090013 and R305A110038). Many thanks to Tanya Wright for her helpful comments on a previous version of this manuscript and to the children who participated in this research.

\section{References}

[1] E. D. Hirsch, "Reading comprehension requires knowledge of words and the world," American Educator, vol. 27, pp. 1316-1322, 1328-1329, 1348, 2003.

[2] A. M. Pinkham, T. Kaefer, and S. B. Neuman, Eds., Knowledge Development in Early Childhood: How Young Children Build Knowledge and Why It Matters, Guilford, New York, NY, USA, 2012.

[3] T. Kaefer, S. B. Neuman, and A. M. Pinkham, Preexisting Background Knowledge Influences Socioeconomic Differences in Preschooler's Word Learning and ComprehenSion, Reading Psychology, 2013.

[4] A. M. Shapiro, "How including prior knowledge as a subject variable may change outcomes of learning research," American Educational Research Journal, vol. 41, no. 1, pp. 159-189, 2004.

[5] A. M. Pinkham and S. B. Neuman, "Early literacy development," in Handbook on Family Literacy, B. H. Wasik and B. Van Horn, Eds., vol. 2, pp. 23-37, Routledge, New York, NY, USA, 2012.

[6] A. E. Cunningham and K. E. Stanovich, "What reading does for the mind," American Educator, vol. 22, no. 1-2, pp. 8-15, 1998.

[7] S. B. Neuman and D. C. Celano, Giving Our Children a Fighting Chance: Poverty, Literacy, and the Development of Information Capital, Teachers College Press, New York, NY, USA, 2012.

[8] B. Rogoff, The Cultural Nature of Human Development, Oxford University Press, New York, NY, USA, 2003.

[9] L. M. Morrow, "Young children's responses to one-on-one story readings in school settings," Reading Research Quarterly, vol. 13, no. 1, pp. 89-107, 1988.

[10] S. E. Mol, A. G. Bus, M. T. De Jong, and D. J. H. Smeets, "Added value of dialogic parent-child book readings: a meta-analysis," Early Education and Development, vol. 19, no. 1, pp. 7-26, 2008.

[11] National Early Literacy Panel, Developing Early Literacy, National Institute for Literacy, Washington, DC, USA, 2008.

[12] S. B. Newman, "Children engaging in storybook reading: the influence of access to print resources, opportunity, and parental 
interaction," Early Childhood Research Quarterly, vol. 11, no. 4, pp. 495-513, 1996.

[13] E. Hepburn, B. Egan, and N. Flynn, "Vocabulary acquisition in young children: the role of the story," Journal of Early Childhood Literacy, vol. 10, no. 2, pp. 159-182, 2010.

[14] A. M. Pinkham, "Learning by the book: The importance of books for young children's knowledge acquisition," in Knowledge Development in Early Childhood: Sources of Learning and Classroom Implications, A. M. Pinkham, T. Kaefer, and S. B. Neuman, Eds., pp. 90-108, Guilford Press, New York, NY, USA, 2012.

[15] B. Tversky, "Development of taxonomic organization of named and pictured categories," Developmental Psychology, vol. 21, no. 6, pp. 1111-1119, 1985.

[16] L. W. Barsalou, "Context-independent and context-dependent information in concepts," Memory and Cognition, vol. 10, no. 1, pp. 82-93, 1982.

[17] J. Lucariello, A. Kyratzis, and K. Nelson, "Taxonomic knowledge: what kind and when?" Child Development, vol. 63, no. 4, pp. 978-998, 1992.

[18] S. A. Gelman, "Learning from others: children's construction of concepts," Annual Review of Psychology, vol. 60, pp. 115-140, 2009.

[19] D. Z. Hambrick, "Why are some people more knowledgeable than others? A longitudinal study of knowledge acquisition," Memory and Cognition, vol. 31, no. 6, pp. 902-917, 2003.

[20] E. M. Markman, Categorization and Naming in Children: Problems of Induction, MIT Press, Cambridge, Mass, USA, 1989.

[21] M. A. Gernsbacher, Language Comprehension as Structure Building, Lawrence Erlbaum, Hillsdale, NJ, USA, 1990.

[22] P. van den Broek, D. N. Rapp, and P. Kendeou, "Integrating memory-based and constructionist processes in accounts of reading comprehension," Discourse Processes, vol. 39, no. 2-3, pp. 299-316, 2005.

[23] T. Kaefer and S. B. Neuman, "A bidirectional relationship between conceptual organization and word learning," Child Development Research, vol. 2013, Article ID 298603, 8 pages, 2013.

[24] S. B. Neuman and T. Kaefer, "The effects of group size on word knowledge and conceptual development," The Elementary School Journal, vol. 113, no. 4, pp. 589-608, 2013.

[25] S. B. Neuman, T. Kaefer, and A. M. Pinkham, "Improving low-income preschoolers' word and world knowledge: the effects of content-rich instruction," Manuscript submitted for publication.

[26] S. B. Neuman, E. H. Newman, and J. Dwyer, "Educational effects of a vocabulary intervention on preschoolers word knowledge and conceptual development: a cluster-randomized trial," Reading Research Quarterly, vol. 46, no. 3, pp. 249-272, 2011.

[27] A. Van Kleeck, "Providing preschool foundations for later reading comprehension: the importance of and ideas for targeting inferencing in storybook-sharing interventions," Psychology in the Schools, vol. 45, no. 7, pp. 627-643, 2008.

[28] S. A. Gelman, The Essential Child: Origins of Essentialism in Everyday Thought, Oxford University Press, New York, NY, USA, 2003.

[29] B. Rehder and R. Hastie, "Category coherence and categorybased property induction," Cognition, vol. 91, no. 2, pp. 113-153, 2004.
[30] D. DeMarie-Dreblow, "Relation between knowledge and memory: a reminder that correlation does not imply causality," Child Development, vol. 62, pp. 484-498, 1991.

[31] S. A. Gelman and J. D. Coley, "The Importance of Knowing a Dodo Is a Bird: categories and Inferences in 2-year-old children," Developmental Psychology, vol. 26, no. 5, pp. 796-804, 1990.

[32] N. S. Johnson and J. M. Mandler, "A tale of two structures: underlying and surface forms in stories," Poetics, vol. 9, no. 13, pp. 51-86, 1980.

[33] D. E. Rumelhart, "Notes on a schema for stories," in Representation and Understanding: Studies in Cognitive Science, D. G. Bobrow and A. Collins, Eds., pp. 211-236, University of Michigan Press, Ann Arbor, Mich, USA, 1975.

[34] S. A. Gelman, E. A. Ware, and F. Kleinberg, "Effects of generic language on category content and structure," Cognitive Psychology, vol. 61, no. 3, pp. 273-301, 2010.

[35] T. Nazzi and A. Gopnik, "A shift in children's use of perceptual and causal cues to categorization," Developmental Science, vol. 3, no. 4, pp. 389-396, 2000.

[36] Z. Estes, S. Golonka, and L. L. Jones, "Thematic Thinking. The Apprehension and Consequences of Thematic Relations," Psychology of Learning and Motivation-Advances in Research and Theory, vol. 54, pp. 249-294, 2011.

[37] L. Dunn and L. Dunn, Peabody Picture Vocabulary Test-III, American Guidance Services, Circle Pines, Minn, USA, 1998.

[38] W. R. Shadish, T. D. Cook, and D. T. Campbell, Experimental and Quasi-Experimental Designs for Generalized Causal Inference, Houghton-Mifflin, Boston, Mass, USA, 2002.

[39] G. Csibra and G. Gergely, "Social learning and social cognition: the case for pedagogy," in Processes of Change in Brain and Cognitive Development, Attention and Performance XXI, Y. Munakata and M. H. Johnson, Eds., pp. 249-274, Oxford University Press, New York, NY, USA, 2006.

[40] P. A. Ganea, L. Ma, and J. S. DeLoache, "Young children's learning and transfer of biological information from picture books to real animals," Child Development, vol. 82, no. 5, pp. 1421-1433, 2011.

[41] A. M. Pinkham, S. B. Neuman, and A. S. Lillard, "Effects of word frequency on vocabulary development," in Proceedings of the Annual Meeting of the Literacy Research Association, Jacksonville, Fla, USA, December 2011.

[42] J. S. Horst, K. L. Parsons, and N. M. Bryan, "Get the story straight: contextual repetition promotes word learning from storybooks," Frontiers in Psychology, vol. 2, pp. 1-11, 2011.

[43] E. J. Marsh, M. L. Meade, and H. L. Roediger III, "Learning facts from fiction," Journal of Memory and Language, vol. 49, no. 4, pp. 519-536, 2003.

[44] K. E. Stanovich, "Matthew effects in reading: some consequences of individual differences in the acquisition of literacy," Reading Research Quarterly, vol. 21, pp. 360-407, 1986.

[45] J. Cohen, Statistical Power Analysis for the Behavioral Sciences, Lawrence Erlbaum Associates, Hillsdale, NJ, USA, 2nd edition, 1988.

[46] H. Nassaji, "The relationship between depth of vocabulary knowledge and L2 learners' lexical inferencing strategy use and success," Canadian Modern Language Review, vol. 61, no. 1, article 107, 2004.

[47] E. Reese and A. Cox, "Quality of adult book reading affects children's emergent literacy," Developmental psychology, vol. 35, no. 1, pp. 20-28, 1999. 
[48] G. J. Whitehurst, D. S. Arnold, J. N. Epstein, A. L. Angell, M. Smith, and J. E. Fischel, "A picture book reading intervention in day care and home for children from low-income families," Developmental Psychology, vol. 30, no. 5, pp. 679-689, 1994.

[49] A. M. Glenberg and W. E. Langston, "Comprehension of illustrated text: pictures help to build mental models," Journal of Memory and Language, vol. 31, no. 2, pp. 129-151, 1992.

[50] M. T. de Jong and M. J. A. J. Verhallen, "Video storybooks: a way to empower children at risk," in Technology as a Support for Literacy Achievements for Children at Risk, A. Shamir and O. Korat, Eds., pp. 33-45, Springer, New York, NY, USA, 2013.

[51] A. M. Pinkham, S. B. Neuman, and T. Kaefer, "Infantsonline processing of baby videos: an eye movement study," Manuscript submitted for publication.

[52] C. Robbins and L. C. Ehri, "Reading storybooks to kindergartners helps them learn new vocabulary words," Journal of Educational Psychology, vol. 86, no. 1, pp. 54-64, 1994.

[53] M. M. Pike, M. A. Barnes, and R. W. Barron, "The role of illustrations in children's inferential comprehension," Journal of Experimental Child Psychology, vol. 105, no. 3, pp. 243-255, 2010.

[54] T. S. Wright, "What classroom observations reveal about oral vocabulary instruction in kindergarten," Reading Research Quarterly, vol. 47, no. 4, pp. 353-355, 2012.

[55] J. E. Gonzalez, S. Pollard-Durodola, D. C. Simmons et al., "Developing low-income preschoolers' social studies and science vocabulary knowledge through content-focused shared book reading," Journal of Research on Educational Effectiveness, vol. 4, no. 1, pp. 25-52, 2011.

[56] S. D. Pollard-Durodola, J. E. Gonzalez, D. C. Simmons et al., "The effects of an intensive shared book-reading intervention for preschool children at risk for vocabulary delay," Exceptional Children, vol. 77, no. 2, pp. 161-183, 2011.

[57] C. C. Pappas, "The information book genre: Its role in integrated science literacy research and practice," Reading Research Quarterly, vol. 41, no. 2, pp. 226-250, 2006.

[58] C. Tower, “'It's a snake, you guys!': the power of text characteristics on children's responses to information books," Research in the Teaching of English, vol. 37, no. 1, pp. 55-88, 2002.

[59] N. K. Duke, "3.6 minutes per day: the scarcity of informational texts in first grade," Reading Research Quarterly, vol. 35, no. 2, pp. 202-224, 2000.

[60] D. Skolnick and P. Bloom, "What does Batman think about SpongeBob? Children's understanding of the fantasy/fantasy distinction," Cognition, vol. 101, no. 1, pp. B9-B18, 2006.

[61] R. A. Richert, A. B. Shawber, R. E. Hoffman, and M. Taylor, "Learning from fantasy and real characters in preschool and kindergarten," Journal of Cognition and Development, vol. 10, no. $1-2$, pp. 41-66, 2009. 

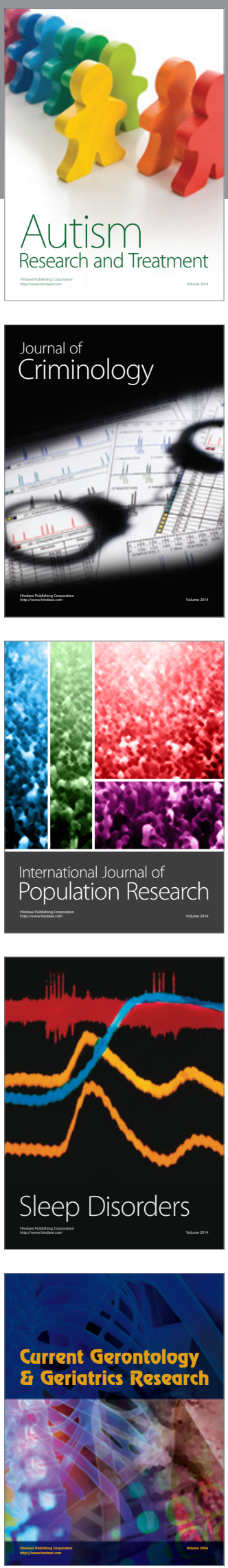
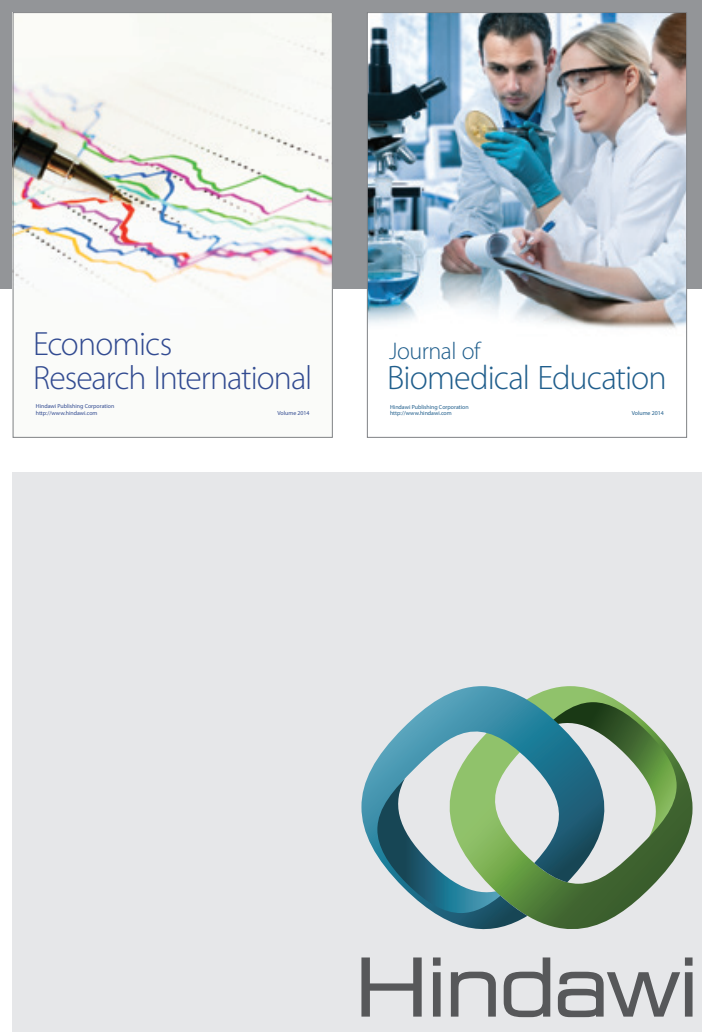

Submit your manuscripts at

http://www.hindawi.com
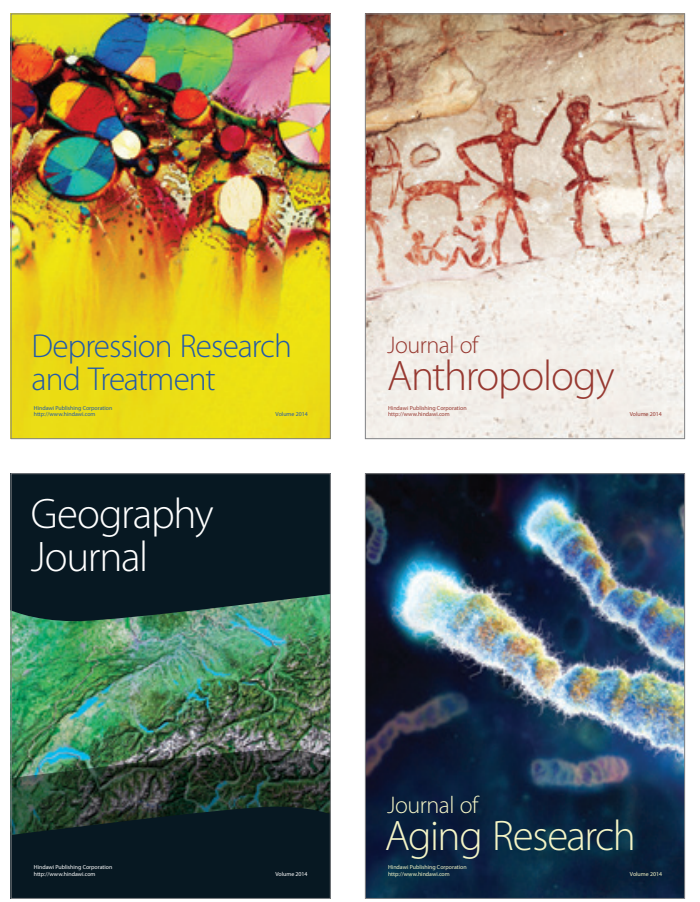
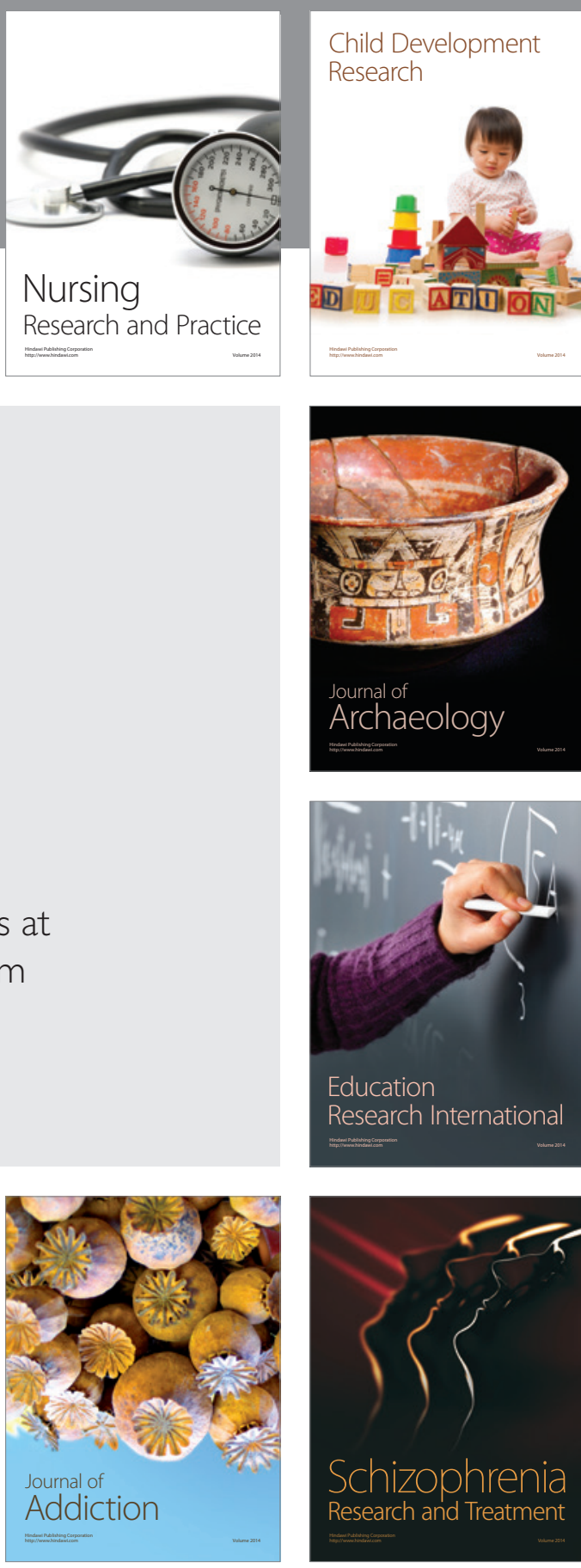

(D)
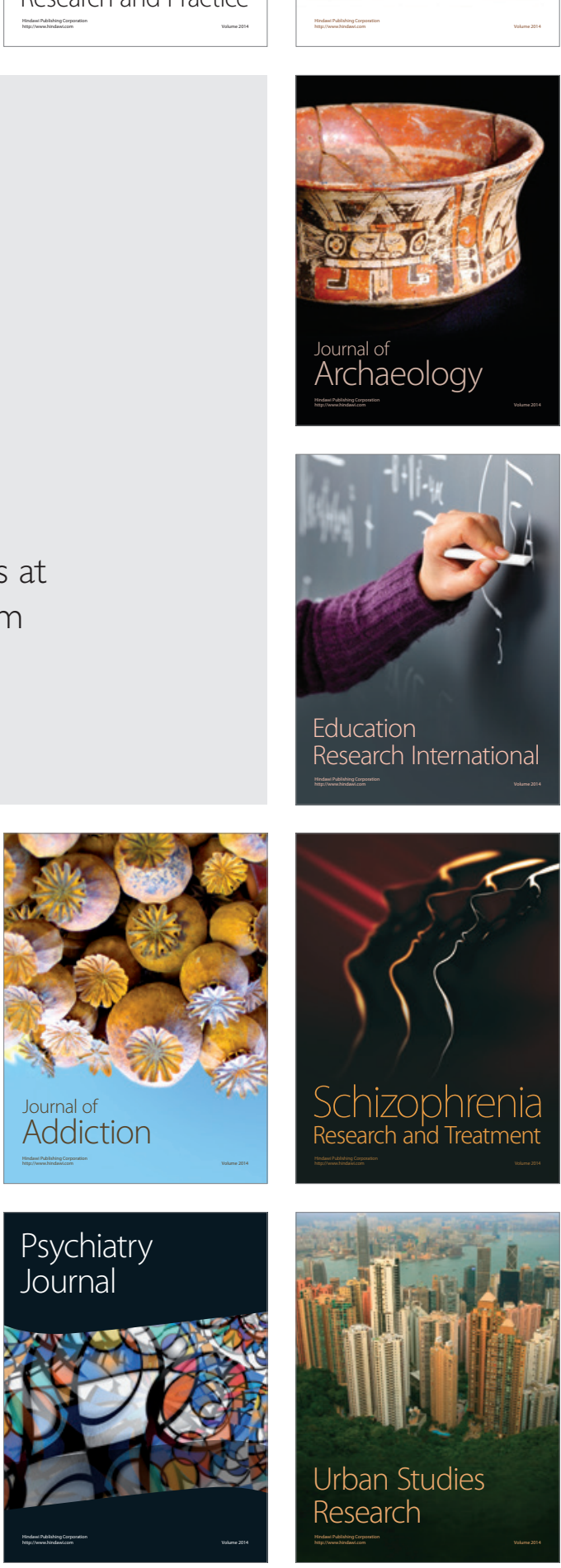